\title{
A Epidemiologia na Avaliação dos Serviços de Saúde: A Discussão da Qualidade.
}

\section{Luiz Carlos de Oliveira Cecilio*}

Todos os enfoques de planejamento trabalhados na área da saúde "dialogam", implicita ou explicitamente, a Epidemiologia. Tanto é assim que, o mais clássico dos métodos de programação para a Saúde, o CENDES/OPS, de meados da década de 60, apropria-se de todo o instrumental epidemiológico que, todavia, gera em torno de teóricas adotadas por uma certa Epidemiologia de recorte funcionalista baseada na teoria dos sistemas.

$\mathrm{Na}$ década de 80 , quando Mário Testa faz um conjunto de reflexões sobre o planejamento estratégico para a Saúde, ocupa-se, entre outras coisas, de fazer um agudo questinamento do dignóstico do tipo "objetivo" e de recorte positivista adotado pelo CENDES/OPS, advoga a necessidade de outros "diagnósticos" que incorporem o conceito de classes sociais, de conflitos e outras categorias que colocam em cheque as idéias de "neutralidade" e "objetividade" embutidos no planejamento normativo.

O próprio Planejamento Estratégico Situacional, conforme desenvolvido por Carlos Matus (embora não seja voltado originalmente para a Saúde e portanto não se ocupe especificamente da questão de Epidemiologia) oferece elementos para a crítica à pretensa objetividade dos diagnósticos tradicionais, na medida em que cada ator faz recortes interessados e diferenciados de uma mesma "realidade" em função de seus interesses e de sua ação concreta. Assim, existem tantos "diagnósticos" quanto atores em situação.

Pelo que foi rapidamente colocado no parágrafo anterior, é fácil verificar a afinidade ou proximidade entre Planejamento e Epidemiologia, embora uma prática integrada e de cooperação entre as duas disciplinas nem sempre aconteça. Na Experiência do Laboratório de Planejamento e Administração (LAPA)

\footnotetext{
* Professor Doutor do Departamento de Medicina Preventiva da Faculdade de Ciências Médicas da UNICAMP
} 
do DMPS da Unicamp, o processo de planejamento tem sido conduzido de uma forma tão próxima àquele de gestão que ambos têm sido considerados como uma só coisa. Nessa medida, e como conseqüência, a Epidemiologia tem assumido, cada vez mais, um papel de destaque no processo de gestão.

$O$ modelo de gestão trabalhado pelo LAPA enfatiza a necessidade de se estabelecer um intenso processo de comunicação dentro da instituição, no sentido do entendimento para a ação. Ou seja, comunicação aqui tomada para além do seu sentido mais convencional, mas dentro de uma perspectiva (habermasiana) de um certo "agir comunicativo", de criação de consensos em torno de determinado(s) projeto(s). Para o fortalecimento ou melhoria da comunicação dentro da organização, alguns dispositivos são adotados:

1 - horizontalização (achatamento) dos organogramas, com redução radical dos níveis intermediários de comando, poder e decisão.

2 - direção colegiada em todos os níveis da organização, no sentido de incorporar um número maior de trabalhadores ao processo decisório e romper com a solidão dos dirigentes e/ou gerentes.

3 - ênfase na lateralização da comunicação dentro da organização, isto é, entre as unidades de trabalho ou inter-equipes.

4 - ênfase na avaliação permanente de processos e resultados no interior da instituição, realizada pelos vários colegiados.

É neste processo de avaliação que entra a importante contribuição dos instrumentos considerados do campo específico da Epidemiologia para o processo de democratização da gestão entre eles, basicamente, determinados indicadores relativos às "populações" que frequentam os serviços de saúde ou neles se inserem como trabalhadores. Aqui valem algumas considerações:

- a incorporação dos instrumentos da Epidemiologia, para o processo de gestão e avaliação da qualidade dos serviços de saúde, implica na apropriação sistemática e dinâmica dos dados produzidos no processo de prestação de serviços, de modo que os mesmos se transformem em "informação gerencial" e deixem de ser apenas um registro burocrático, cujo destino seja engrossar as pastas dos SAMES.

- introduz-se na instituição uma nova postura de valorização da qualidade e do cuidado na coleta dos dados, no sentido de que os mesmos se transformem em informação gerencial de boa qualidade. Como conseqüência, contribui-se para o estabelecimento de uma certa "cultura" de responsabilidade pela informação, que não é comum, de uma maneira geral, na tradição das instituições de saúde.

- a apropriação da informação, em geral na forma de indicadores, coloca o desafio da definição de parâmetros de qualidade para a instituição. Aqui depara-se com uma grande dificuldade, qual seja, a da comparabilidade inter-institucional, em função de perfis assistenciais muito diferenciados. No caso dos hospitais, por exemplo, pesam, entre outros aspectos, o grau de complexidade 
dos procedimentos, o tamanho do hospital e sua forma de inserção no Sistema Único de Saúde (SUS), entre outros.

A consolidação das experiências que têm sido trabalhadas pelo LAPA, na área de gestão hospitalar, na medida em que se valoriza crescentemente os instrumentos tradicionalmente do "domínio".da Epidemiologia, tem colocado algumas questões interessantes para serem debatidas, entre elas o papel do epidemiologista - enquanto um profissional dotado de uma "especialização" - no interior da equipes de gestão. Tem sido necessário equacionar uma certa tensão entre o ser "especialista" (o detentor de um certo saber altamente especializado) e a apropriação deste saber por um número crescente de trabalhadores que o utilizam na sua vida cotidiana.

A apropriação, no interior do referido modelo de gestão, de um conjunto de técnicas e concepções oriundas dos programas de qualidade (TQC e outros) tem se traduzido na necessidade da democratização de um campo de saber anteriormente "privativo"de especialistas. Tanto é assim que, mais e mais equipes operacionais dos hospitais se familiarizam com a construção de taxas, de diagramas de controle, de diagramas de dispersão, cálculo de desvio padrão e outros instrumentos incorporados ao processo gerencial (gestão da rotina).

Além do mais, tem se trabalhado com a implantação de um conjunto de "dispositivos de qualificação da gestão", tais como as comissões de controle de infecção hospitalar, comissões de revisão de óbitos, serviços de saúde do trabalhador em saúde, entre outros, que constituem o campo do que se poderia designar de "Epidemiologia hospitalar" e que, na experiência do LAPA, mais do que um campo especializado e isolado, tem se confundido com o próprio processo de planejamento e gestão, enriquecendo-o e, mais do que isso, constituindo-o. 